\title{
MATURAÇÃO, FORMAS DE SECAGEM E QUALIDADE FISIOLÓGICADE SEMENTES DE MUCUNA-PRETA ${ }^{1}$
}

\author{
JOÃO NAKAGAWA ${ }^{2}$, CLAUDIO CAVARIANI ${ }^{3}$, CLAUDEMIR ZUCARELI ${ }^{4}$
}

\begin{abstract}
RESUMO - O objetivo deste trabalho foi verificar o efeito das formas de secagem, durante a maturação, sobre o desenvolvimento e a qualidade fisiológica de sementes de mucuna-preta. No primeiro experimento, inflorescências foram etiquetadas no início de florescimento e as colheitas iniciaram-se duas semanas após; no segundo, as colheitas foram iniciadas 40 dias após $50 \%$ de florescimento das plantas; em ambos, as colheitas foram feitas a intervalos semanais até o estádio de vagens secas. As sementes de cada colheita do primeiro experimento foram secadas, em condições ambientais de laboratório, no interior de vagens fechadas ou abertas (sementes expostas) e determinados a massa de 100 sementes, o comprimento, a largura e a espessura das sementes, enquanto no segundo foram secadas no interior de vagens fechadas ou extraídas das vagens e submetidas ao teste de germinação. A secagem no interior das vagens promove o desenvolvimento de sementes imaturas, antecipa a formação de sementes duras e aumenta o número dessas nas imaturas comparativamente às sementes secadas em vagens abertas ou após a extração.
\end{abstract}

Termos para indexação: Mucuna aterrima, colheita, germinação, dormência

\section{MATURATION, DRYINGAND PHYSIOLOGICAL QUALITY OF VELVET BEAN SEEDS}

\begin{abstract}
The purpose of this study was to investigate the effect of drying methods during maturation of velvet bean seeds on their development and physiological quality. In the first experiment, inflorescences were tagged at the beginning of flowering and harvests started two weeks later; in the second experiment, harvests started 40 days after $50 \%$ flowering. In both experiments harvests were made at regular intervals until the pods were dry. The seeds of each harvest time in the first experiment were dried in intact pods or in opened pods (with exposed seeds) at ambient laboratory conditions and evaluated in relation to 100 seeds weight, length, width and thickness of seeds. In the second experiment the seeds of each harvest were dried in intact pods or shelled, under same conditions as the first one and submitted to the germination test. Drying of intact pods abbreviated the development of immature seeds, hastened the onset of hard seeds and increased the hard seed content in the immature seeds comparativally with those dried exposed or shelled.
\end{abstract}

Index terms: Mucuna aterrima, harvest, germination, dormancy

\section{INTRODUÇ̃̃O}

A mucuna-preta (Mucuna aterrima Piper et Tracy Holland) é uma leguminosa anual, herbácea, rasteira, vigorosa, com ramos trepadores e desenvolvidos (Wutke, 1993). É utilizada como adubação verde, podendo ser empregada, ainda, como forragem ou, triturando-se os grãos, como suplemento protéico aos animais (Calegari, 1995).

É resistente a nematóides do gênero Meloidogyne, apresentando efeito alelopático sobre a tiririca (Wutke, 1993).

\footnotetext{
${ }^{3}$ Prof. Assistente, Dr., FCA-UNESP/Botucatu.

${ }^{4}$ Eng $^{\circ}$ Agro $^{\circ}$, Doutorando do Programa de Pós-Graduação em Agronomia Agricultura; FCA-UNESP/Botucatu.

${ }^{1}$ Submetido em 05/11/2003. Aceito para publicação em 06/10/2004.

${ }^{2}$ Prof. Titular Aposentado, Voluntário, FCA-UNESP/Botucatu; Cx.P. 237, 18603-970. Botucatu-SP; Bolsista do CNPq, e-mail: secdamv@fca.unesp.br
} 
O ciclo da cultura varia de 210 a 260 dias (Calegari, 1995). Em condições de Jaboticabal-SP, com semeadura em final de novembro, o início do florescimento foi verificado em meados de abril e a maturidade fisiológica das sementes atingida 78 dias após o florescimento (Vieira et al., 1988).

As sementes de mucuna-preta podem apresentar dormência oriunda da impermeabilidade do tegumento a água (Brasil, 1992), constituindo-se nas chamadas sementes duras que ocorrem em maior porcentagem logo após a colheita (Maeda \& Lago, 1986 a, b). Os lotes de sementes dessa espécie podem apresentar de 60 a $80 \%$ de sementes duras, nas recémcolhidas (Maeda \& Lago, 1986a), fato que traz transtornos ao agricultor, ao comerciante e ao analista de sementes. Esta dormência, segundo trabalho de Nimer et al. (1983), está relacionada ao tamanho das sementes, à posição da vagem no rácemo e à posição das sementes na vagem, nesta seqüência de grau de influência; dessa forma, as sementes menores e as originárias do terço inferior dos rácemos apresentaram maior percentual de sementes duras, enquanto para posição das sementes nas vagens, notaram-se diferenças entre as posições, mas não se constatou uma ordenação lógica desse efeito. Barbedo et al. (1988) também constataram maior porcentagem de dureza nas sementes menores; Wutke et al. (1995), entretanto, não observaram diferenças das porcentagens de sementes duras entre os tamanhos.

A superação da dormência da mucuna-preta pode ser obtida através de métodos mecânicos (Maeda \& Lago, 1986a; Silva et al., 2001), químicos (Maeda \& Lago, 1986a) e físicos (Wutke et al., 1995), porém tal procedimento nem sempre é necessário, pois o índice de sementes duras diminui sensivelmente nos primeiros meses, tornando-se baixo após seis meses de armazenamento (Maeda \& Lago, 1986b).

A dormência das sementes é um fenômeno que se instala no decorrer da maturação, sendo uma estratégia das plantas para evitar que ocorra a viviparidade ou germinação na própria planta. Em estudos de maturação, esse fenômeno dificulta as avaliações e a definição do momento em que as sementes adquirem a máxima capacidade de germinação.

Para estudar a maturação, as sementes, que são colhidas a intervalos regulares após a antese podem ser testadas quanto à germinação quando ainda úmidas (recém-colhidas) ou secas, isto é, após deixá-las entrar em equilíbrio higroscópico com ambiente de baixa umidade relativa (Carvalho, 1974). A secagem das sementes pode ser realizada dentro ou fora dos frutos, como em trabalhos com soja (Adams \& Rinne, 1981; Morais et al., 2001a) e caupi (Morais et al., 2001b). Em mucuna-preta, Vieira et al. (1988) retiraram as sementes das vagens, deixando-as secar em ambiente de laboratório, antes de avaliarem a germinação. Nesses trabalhos, em função da metodologia utilizada, os resultados têm sido diferentes para as sementes imaturas, com maiores germinações para as sementes secas que para as úmidas (Carvalho, 1974) ou quando secas no interior das vagens (Adams \& Rinne, 1981). Em sementes de quiabeiro, cv. Santa Cruz-47, Setúbal et al. (1996) verificaram que a secagem das sementes dentro do fruto, quando feita de maneira mais lenta, ou seja, em condições de ambiente, possibilitou germinação das imaturas semelhante às maduras, porém resultou, também, em maior percentual de sementes duras. A interpretação dos resultados de germinação e vigor, nesses trabalhos (Adams \& Rinne, 1981; Carvalho, 1974; Vieira et al., 1988; Setúbal et al., 1996; Morais et al., 2001a,b), foi auxiliada pela avaliação de outras características das sementes, de natureza morfológica, física ou bioquímica, além das fisiológicas.

Tendo em vista esses aspectos encontrados na literatura, o presente trabalho teve por objetivos estudar o desenvolvimento das sementes e verificar a ocorrência de sementes duras durante a maturação de mucuna-preta em função da forma de secagem a qual foram submetidas, dentro ou fora das vagens.

\section{MATERIAL E MÉTODOS}

O trabalho foi conduzido em solo classificado como Terra Roxa Estruturada distrófica, textura argilosa (Carvalho et al., 1983), atualmente considerado Nitossolo Vermelho (Oliveira et al., 1999), da Fazenda Experimental Lageado (FEL) do Campus de Botucatu, UNESP, localizada no município de Botucatu, SP, com altitude de $815 \mathrm{~m}$, latitude de $22^{\circ} 51^{\prime}$ ' Sul e longitude de $48^{\circ} 26^{\prime}$ WGrw, e parte em laboratório.

A cultura da mucuna-preta foi conduzida em espaldeira de plantas de milho, semeada em outubro, com espaçamento de $1,0 \mathrm{~m}$ entre linhas e com cinco plantas por metro linear. Em dezembro, quarenta dias após a emergência das plântulas de milho, semeou-se a mucuna-preta, na entre linha, distante cerca de $0,30 \mathrm{~m}$ das plantas de milho, adotando-se os mesmos espaçamentos desse. $\mathrm{O}$ início do florescimento da mucunapreta ocorreu em 05 de maio e $50 \%$ de florescimento (DAF) foi atingido em 16 de maio.

No Experimento 1, inflorescências em início de formação foram etiquetadas. Nestas, duas semanas após a abertura das primeiras flores, que ocorre na base do rácemo, iniciou-se a colheita das vagens, em intervalos de quatro e cinco dias no 
princípio do desenvolvimento e depois semanalmente, num total de 14 colheitas, correspondendo a um período de 92 dias após o início do florescimento. Em cada colheita, duas vagens, dispostas em posição oposta no eixo, foram retiradas do rácemo; uma das vagens foi aberta, deixando as sementes expostas, e a outra foi mantida fechada. Ambas as vagens foram colocadas em bandejas e deixadas secar em ambiente natural de laboratório. Dois meses após a última colheita, procedeu-se a extração das sementes, das vagens fechadas e das abertas, para todas as épocas de colheita, para procederemse as avaliações.

Em cada colheita foi avaliada a coloração predominante das vagens e sementes recém-colhidas e úmidas.

Com auxílio de paquímetro foram medidos o comprimento, a largura e a espessura das sementes secas, no mínimo de três unidades para cada época de colheita e sistema de secagem. A seguir, determinou-se a massa das sementes, em balança com precisão de $0,01 \mathrm{~g}$, e calculou-se a massa de 100 sementes.

No Experimento 2 foram feitas colheitas semanais de rácemos, iniciadas no quadragésimo dia após os $50 \%$ de florescimento (DAF) até o estádio de vagens secas, observado aos 89 DAF, num total de oito colheitas.

As colheitas dos rácemos foram feitas em cinco locais distintos no campo (6 a 7 rácemos por local), num total de 30 a 35 rácemos, que originaram cerca de 400 a 450 vagens por colheita.

Após cada colheita, os rácemos foram levados, acondicionados em sacos de plástico vedados, para o laboratório onde se retirou quatro sub-amostras de 15 sementes para a determinação do teor de água, pelo método da estufa a $105^{\circ} \pm 3^{\circ} \mathrm{C}$ por $24 \mathrm{~h}$ (Brasil, 1992); estas foram utilizadas, também, para a obtenção da massa seca de 100 sementes.

As vagens dos rácemos foram separadas ao longo do eixo: a metade delas foi aberta, extraídas as suas sementes e estas postas em bandejas para secar em condições ambientais de laboratório. A outra metade das vagens foi posta em bandejas e deixada secar nas mesmas condições; nessa as sementes foram extraídas por ocasião das avaliações quando as vaens encontravam-se secas.

Em cada colheita, as vagens recém-colhidas foram avaliadas visualmente quanto ao seu estádio de maturação, pela coloração e aspecto, calculando-se o percentual de cada estádio na amostra coletada. Foi também avaliada a coloração das sementes, nas vagens que foram abertas logo após a colheita, portanto nas sementes úmidas, anotando-se a coloração predominante.

As sementes secas em ambiente de laboratório (à sombra), fora e dentro das vagens, foram submetidas ao teste de germinação após dois meses da colheita. Quatro repetições de 50 sementes foram empregadas para cada momento de colheita e condição de secagem para avaliação da germinação. O teste foi conduzido em papel toalha (RP), umedecido com água na proporção de três vezes o peso do substrato seco, à temperatura de $30^{\circ} \mathrm{C}$. As contagens foram feitas aos sete e quatorze dias; o teste foi prorrogado por mais sete dias, devido a presença de sementes que apenas iniciaram a germinação. As avaliações das plântulas e sementes seguiram os critérios das Regras para Análise de Sementes (Brasil, 1992).

Nos Experimentos 1 e 2 foram ajustadas equações de regressão de até $3^{\circ}$ grau às características avaliadas, em função das datas de colheita. No Experimento 1, valendo-se da equação de regressão ajustada, foi calculado para cada característica o ponto de máximo, dentro do intervalo de tempo avaliado, ou seja, das colheitas.

\section{RESULTADOS E DISCUSSÃO}

\section{Experimento 1}

As vagens, nas três primeiras colheitas, apresentaram cor-verde (Tabela 1); a seguir passaram a verde-clara e a verde clara/amarelada, tonalidade que permaneceu por cerca de um mês; seguiu-se a coloração amarelada, para nas duas últimas colheitas tornarem-se pretas. Nesses períodos, as sementes passaram gradativamente, da coloração branca com listras vermelha-escuras, para vermelha-escura, vermelha, vermelha-clara, vermelha-clara com escurecimento próximo ao hilo, que foi aumentando até o total escurecimento das sementes, para ao final ficarem pretas brilhante. Em todas essas fases de mudança de coloração, o hilo sempre foi branco. Com a secagem, essas sementes, independente da coloração inicial, ficaram todas pretas e com hilo branco, tanto as secadas no interior das vagens abertas como nas fechadas, atingindo o aspecto típico da espécie (Calegari, 1995).

Pelas curvas obtidas, a partir das equações de regressão ajustadas, para massa de 100 sementes (Figura 1), comprimento (Figura 2), largura (Figura 3) e espessura (Figura 4) das sementes, em função das épocas de colheita, verificase que os aumentos na massa e no tamanho das sementes secadas no interior das vagens abertas foram diferentes daquelas secadas nas vagens fechadas. Assim, os valores máximos foram atingidos antes para aquelas secadas com as 
vagens fechadas. Valendo-se das equações ajustadas, calcularam-se os valores de máximo para cada característica; esses máximos para massa de 100 sementes, comprimento, largura e espessura foram obtidos, respectivamente, aos 72,9 DAF, 69,0 DAF, 62,1 DAF e 72,4 DAF, para sementes secadas nas vagens fechadas e aos 92,0 DAF, 78,5 DAF, 78,8 DAF e 92,0 DAF, para sementes das vagens abertas.

De acordo com esses resultados, quando vagens imaturas de mucuna-preta são destacadas das plantas, as sementes em seu interior podem ter seu tamanho e massa aumentados, quando secadas lentamente, indicando que há translocação de compostos das vagens para as sementes. Já quando há uma secagem rápida, no presente trabalho representada pelas vagens abertas, onde as sementes ficaram em contato direto com o ambiente e praticamente desligadas das vagens, tal fato não ocorre.

Em alguns trabalhos com Cucurbitáceas (Araújo et al., 1982; Alvarenga et al., 1984), tem-se verificado que o armazenamento de frutos imaturos mais novos, em condições ambientais, propicia aumento no conteúdo de massa seca das sementes. Como as vagens imaturas de mucuna-preta são volumosas e suculentas, a secagem em ambiente de laboratório deve ter causado efeito semelhante ao do repouso pós-colheita ou armazenamento dos frutos novos das Cucurbitáceas, resultando nos aumentos de matéria seca e tamanho das sementes.

TABELA 1. Coloração predominante das vagens e das sementes de mucuna-preta recém-colhidas em função das diferentes colheitas das vagens, em dias após o florescimento (DAF). Experimento 1.

\begin{tabular}{ccl}
\hline Tratamentos (DAF) & Coloração da vagem & \multicolumn{1}{c}{ Coloração das sementes } \\
\hline 14 & Verde & branca com listras vermelha-escura \\
18 & Verde & quase toda vermelha-escura \\
22 & Verde & quase toda vermelha-escura \\
27 & Verde-clara & quase toda vermelha \\
32 & Verde clara/amarelada & totalmente vermelha \\
36 & Verde clara/amarelada & totalmente vermelha \\
43 & Verde clara/amarelada & vermelha-clara \\
50 & Verde clara/amarelada & vermelha-clara \\
57 & Verde clara/amarelada & vermelha-clara, com ponto preto próximo ao hilo \\
64 & Amarelada & vermelha-clara, com leve escurecimento próximo ao hi \\
71 & Amarelada & vermelha-clara/escurecida \\
78 & Amarelada/preta & escurecida \\
85 & Preta & preta brilhante \\
92 & Preta & preta brilhante \\
\hline
\end{tabular}

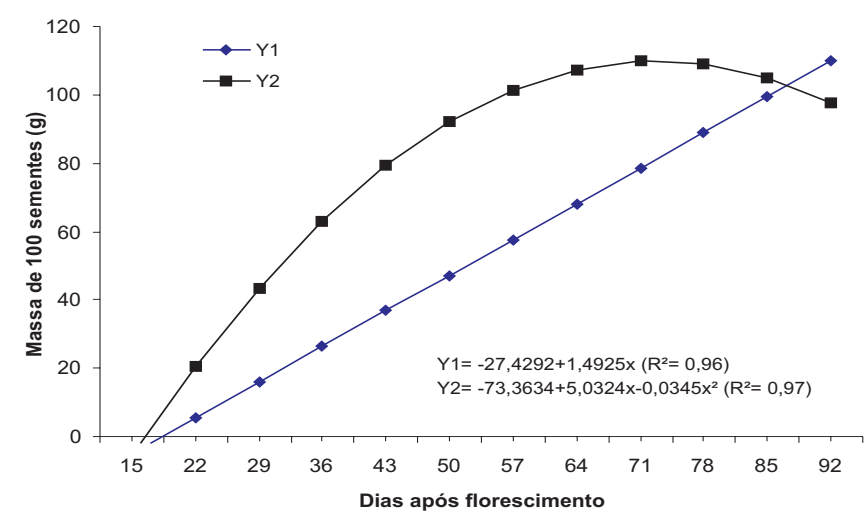

FIGURA 1. Massa de 100 sementes de mucuna-preta secadas no interior de vagens abertas (Y1) e fechadas (Y2), em função das épocas de colheita. Experimento 1.

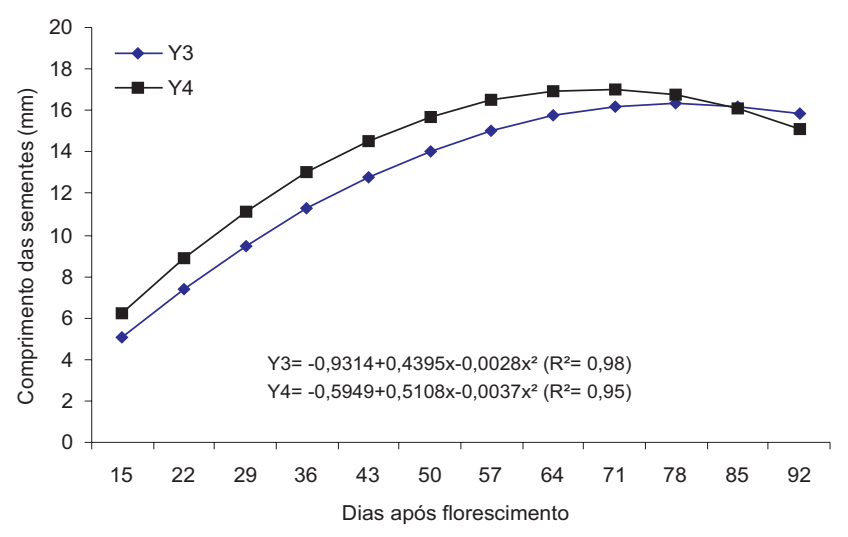

FIGURA 2. Comprimento das sementes de mucuna-preta secadas no interior de vagens abertas (Y3) e fechadas (Y4), em função das épocas de colheita. Experimento 1. 


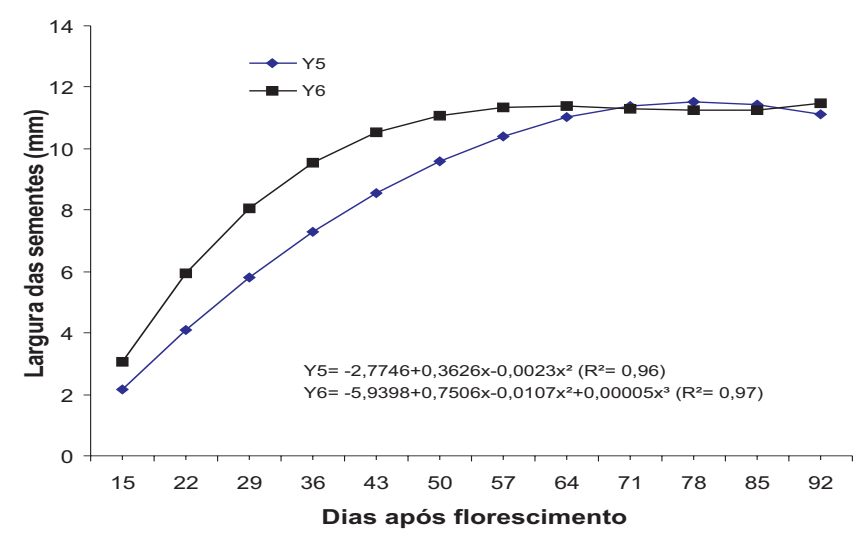

FIGURA 3. Largura das sementes de mucuna-preta secadas no interior de vagens abertas (Y5) e fechadas (Y6), em função das épocas de colheita. Experimento 1.

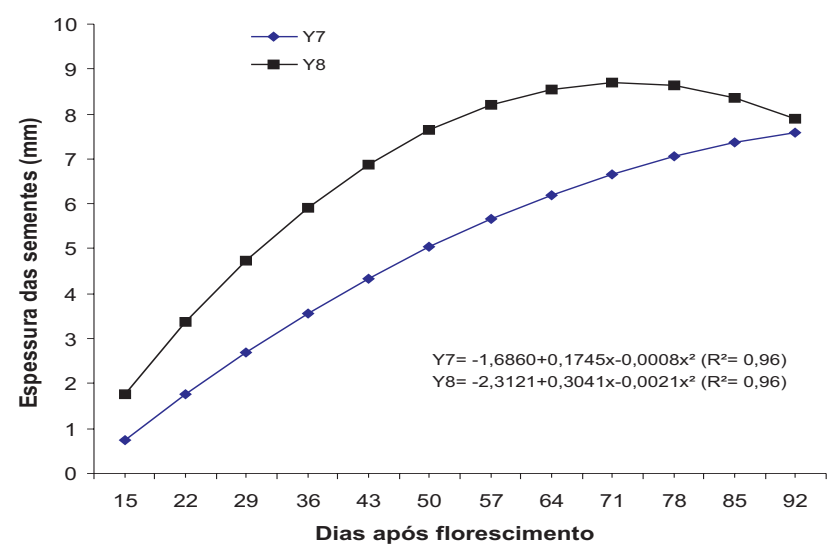

FIGURA 4. Espessura das sementes de mucuna-preta secadas no interior de vagens abertas (Y7) e fechadas (Y8), em função das épocas de colheita. Experimento 1.

Vieira et al. (1988), trabalhando em condições experimentais e ambientais diferentes, constataram que o tamanho das sementes de mucuna preta, avaliado pelo comprimento e largura, em sementes úmidas recém-colhidas, aumentou até os 57 dias após o florescimento, mas o máximo valor de matéria seca foi obtido aos 78 dias. No presente trabalho, embora os máximos valores para o tamanho e a massa tenham sido atingidos mais tardiamente, também o comprimento e a largura foram definidos antes (Figuras $2 \mathrm{e}$ 3) seguindo-se da espessura (Figura 4) e da massa das sementes (Figura 1), indicando uma maior influência da espessura na definição da massa das sementes $(r=0,96)$. Considerando os resultados de ocorrência dos máximos valores de tamanho e massa de 100 sementes (Figuras 1, 2, 3 e 4) e a coloração predominante das vagens e sementes (Tabela 1) por ocasião da colheita, pode-se inferir que colhendo-se vagens com coloração amarelada, contendo sementes em início de escurecimento, estas poderão atingir valores semelhantes de massa e tamanho das sementes das colheitas finais, quando as vagens estão pretas e as sementes pretas brilhantes, desde que secadas no interior de vagens fechadas em condições ambientais à sombra.

\section{Experimento 2}

As vagens apresentaram cor verde-amarelada, durante as quatro primeiras colheitas (Tabela 2); a partir de então começaram a ficar amareladas, para a seguir predominarem as pretas, indicativo de estarem secando. As sementes passaram neste período da coloração vermelha-clara, vermelha-clara com pontos de escurecimento próximo ao hilo, seguindo-se do escurecimento até tornarem-se pretas brilhantes na última colheita. Após a secagem, independente da cor inicial, todas as sementes tornaram-se pretas. O hilo das sementes durante toda a fase de desenvolvimento apresentou cor branca.

Comparando-se as descrições das modificações nas vagens e sementes dos dois experimentos (Tabelas 1 e 2) verificam-se pequenas diferenças nas ocorrências, que devem ser atribuídas às metodologias distintas na definição do momento fisiológico do início das colheitas.

Na Tabela 3 estão apresentadas as equações de regressão ajustadas para as características avaliadas, cuja representação encontram-se nas Figuras 5 a 8.

O teor de água das sementes (Figura 5) era elevado na primeira colheita $(73 \%)$, ocorrendo declínio lento até em torno de 68 dias após $50 \%$ de florescimento (DAF), quando predominavam as vagens verde-amareladas, que apresentavam sementes vermelhas com escurecimento; a partir de então, a perda de água foi rápida devido à secagem das vagens, acompanhada pelo escurecimento das sementes (Tabela 2). Vieira et al. (1988), embora trabalhando em condições ambientais e experimentais diferentes, encontraram teores de água em torno de $73 \%$ entre 37 e 44 dias após o florescimento (flores etiquetadas) e declínio mais acentuado do teor de água a partir de 64 dias, portanto, com comportamento semelhante ao verificado no presente trabalho.

$\mathrm{O}$ aumento da massa seca de 100 sementes foi crescente da primeira a última colheita (Figura 5), indicando que o acúmulo de materiais de reserva nas sementes foi contínuo, mesmo quando a perda de água foi mais acentuada, pois na penúltima colheita ( $82 \mathrm{DAF}$ ) nem todas as vagens estavam secas e o teor de água ainda era elevado (40\%). No trabalho de Vieira et al. (1988), o máximo acúmulo de massa seca foi observado aos 78 dias após o florescimento, portanto antes 
do constatado neste estudo; esta diferença de resultados deve ser atribuída à desuniformidade de florescimento e maturação das vagens no campo, pois Wutke (1993) cita diferenças de 10 dias (140 a 150 dias) na floração e de até 40 dias para colheita das vagens (200 a 240 dias).

Pela Figura 6, verifica-se que houve efeito do tipo de secagem das sementes, se feita fora ou dentro das vagens, sobre a germinação; porém as diferenças de resultados foram mais marcantes para sementes duras. Dessa forma, com a secagem fora das vagens, só obteve-se plântulas normais (germinação) a partir dos 60 dias, quando as sementes por ocasião da colheita estavam com coloração vermelha-clara, com pontos escuros e início do escurecimento (Tabela 1), enquanto as secas no interior das vagens, já na primeira colheita (40 DAF) apresentaram 12\% de germinação. No trabalho de Vieira et al. (1988), no qual a secagem foi realizada fora da vagem, foi observado $0,5 \%$ de plântulas normais aos 50 dias após o florescimento; a partir de então os acréscimos foram contínuos, com valores de $83,5 \%$ aos 85 dias após o florescimento, bem superiores aos desse experimento. Vale ressaltar que no presente trabalho mesmo nas sementes secadas no interior das vagens, cuja germinação foi maior (Figura 6) os valores obtidos nas últimas colheitas do referido experimento não foram atingidos.

TABELA 2. Porcentagem de vagens verde-amarelada, amarelada-preta e preta (seca); descrição da coloração predominante das sementes recém-colhidas em função de épocas de colheita de mucuna-preta, em dias após $50 \%$ de florescimento (DAF). Experimento 2.

\begin{tabular}{|c|c|c|c|c|}
\hline \multirow[t]{2}{*}{ Tratamentos (DAF) } & \multicolumn{3}{|c|}{ Vagens $(\%)$} & \multirow[t]{2}{*}{ Sementes (coloração) } \\
\hline & verde-amarelada & amarelada-preta & preta & \\
\hline 40 & 100 & 0 & 0 & vermelha-clara \\
\hline 47 & 100 & 0 & 0 & $\begin{array}{l}\text { vermelha-clara com escurecimento } \\
\text { próximo ao hilo (manchas escuras) }\end{array}$ \\
\hline 54 & 100 & 0 & 0 & $\begin{array}{l}\text { vermelha-clara com pontos escuros e } \\
\text { escurecimento de algumas }\end{array}$ \\
\hline 61 & 100 & 0 & 0 & $\begin{array}{l}\text { vermelha-clara com pontos escuros, com } \\
\text { escurecimento de algumas }\end{array}$ \\
\hline 68 & 64,1 & 35,9 & 0 & vermelha com escurecimento \\
\hline 75 & 54,9 & 25,5 & 19,6 & escurecida \\
\hline 82 & 16,8 & 14,3 & 68,9 & escurecida \\
\hline 89 & 0 & 4,3 & 95,6 & preta brilhante \\
\hline
\end{tabular}

TABELA3. Equações de regressão ajustadas para as características avaliadas, com secagem das sementes fora (SFV) e dentro da vagem (SDV), em função de épocas de colheita de mucuna-preta. Experimento 2.

\begin{tabular}{llc}
\hline \multicolumn{1}{c}{ Característica } & \multicolumn{1}{c}{ Equação } & $\mathrm{R}^{2}$ \\
\hline Teor de água & $\mathrm{Y}_{1}=215,9037-7,8954 \mathrm{x}+0,1443 \mathrm{x}^{2}-0,0009 \mathrm{x}^{3}$ & 0,98 \\
Massa de 100 sementes & $\mathrm{Y}_{2}=-14,1628+1,0490 \mathrm{x}$ & 0,91 \\
Sementes duras (SFV) & $\mathrm{Y}_{3}=-203,5765+6,7315 \mathrm{x}-0,0429 \mathrm{x}^{2}$ & 0,87 \\
Sementes duras (SDV) & $\mathrm{Y}_{4}=-170,3703+11,5387 \mathrm{x}-0,1683 \mathrm{x}^{2}=0,00075 \mathrm{x}^{3}$ & 0,75 \\
Germinação (SFV) & $\mathrm{Y}_{5}=-6,3289+0,1336 \mathrm{x}$ & 0,33 \\
Germinação (SDV) & $\mathrm{Y}_{6}=63,0693-2,0204 \mathrm{x}+0,0188 \mathrm{x}^{2}$ & 0,66 \\
G+ PA (SFV) & $\mathrm{Y}_{7}=28,6975-1,2782 \mathrm{x}+0,0142 \mathrm{x}^{2}$ & 0,79 \\
G+ PA+SD (SFV) & $\mathrm{Y}_{8}=-174,8786+5,4533 \mathrm{x}-0,0287 \mathrm{x}^{2}$ & 0,90 \\
G+PA (SDV) & $\mathrm{Y}_{9}=107,8805-3,3137 \mathrm{x}+0,0292 \mathrm{x}^{2}$ & 0,75 \\
G+PA+SD (SDV) & $\mathrm{Y}_{10}=91,91$ & n.s. \\
\hline
\end{tabular}

$\mathrm{G}+\mathrm{PA}=$ Germinação + Plântulas anormais

$\mathrm{G}+\mathrm{PA}+\mathrm{SD}=$ Germinação + Plântulas anormais + Sementes duras 


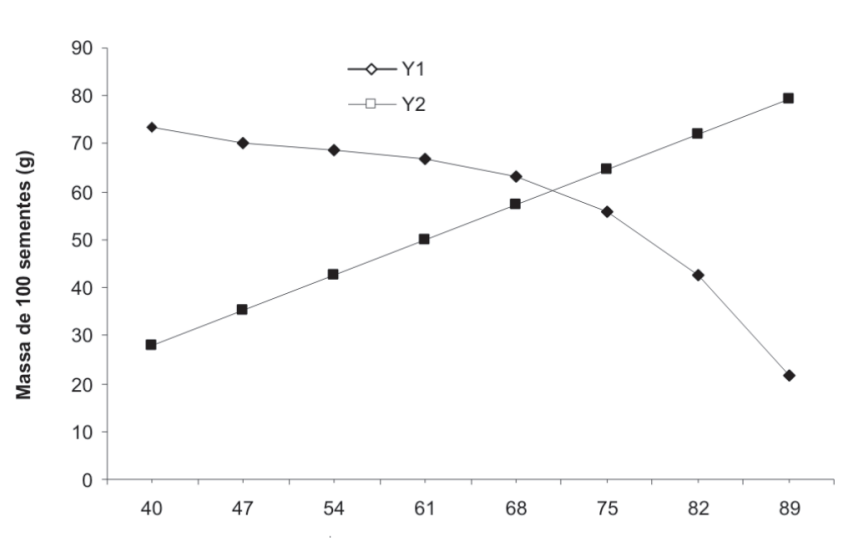

FIGURA 5. Teor de água (Y1) e massa seca de 100 sementes (Y2) de mucuna-preta recém colhidas, em função das épocas de colheita. Experimento 2

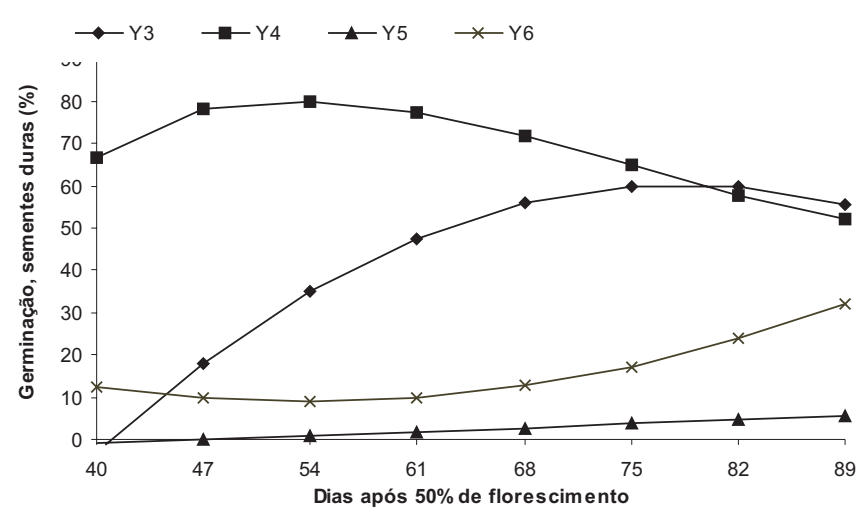

FIGURA 6. Porcentagem de sementes secadas fora das vagens (Y3) e dentro das vagens (Y4) e porcentagem de germinação das sementes secadas fora das vagens (Y5) e dentro das vagens (Y6) de mucuna-preta, em função das épocas de colheitas. Experimento 2.

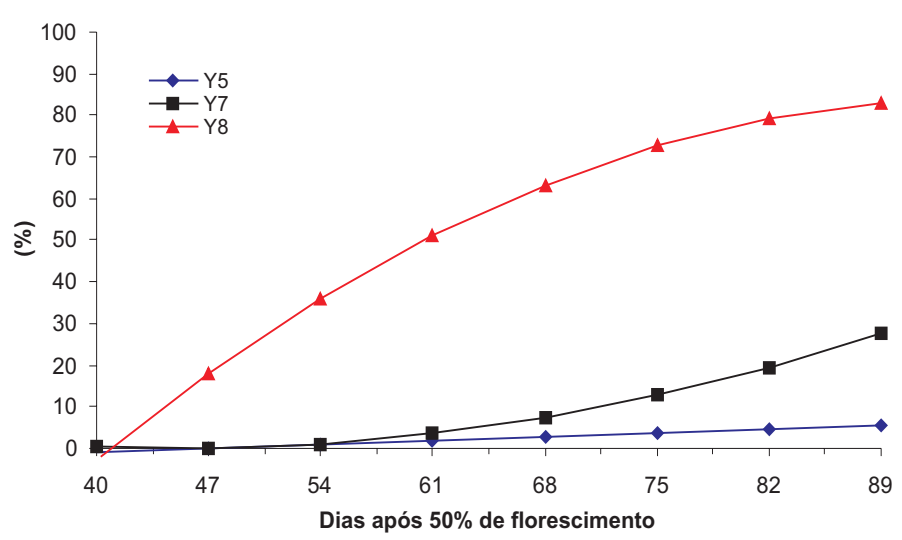

FIGURA 7. Distribuição percentual de germinação, plântulas anormais, sementes duras e sementes mortas de mucuna-preta, cujas sementes foram secadas fora das vagens, em função das épocas de colheitas. Experimento 2.

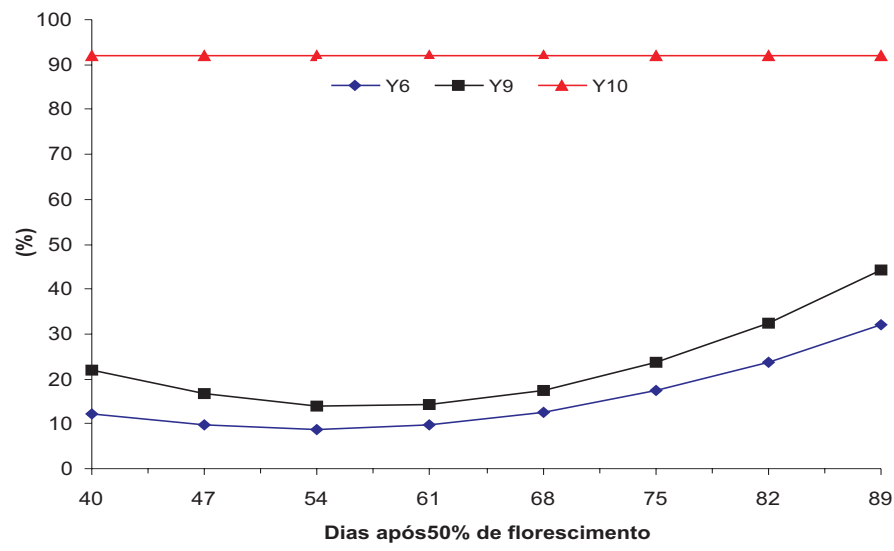

FIGURA 8. Distribuição percentual de germinação, plântulas anormais, sementes duras e sementes mortas de mucuna-preta, cujas sementes foram secadas dentro das vagens, em função das épocas de colheitas. Experimento 2.

O surgimento das sementes duras foi distinto até em torno de 75 dias (Figura 6) para os dois tipos de secagem das sementes; nessa colheita todas as sementes já se encontravam escurecidas. Os valores foram maiores até essa colheita para as secadas no interior das vagens, enquanto para as secadas fora, a dormência foi crescente da primeira época até atingir o máximo aos 78 DAF (60\%).

Ao estudar a distribuição relativa (percentual) das plântulas normais, plântulas anormais, sementes duras e sementes mortas para os dois tipos de secagem (Figuras 7 e 8), verifica-se que para as secadas fora da vagem predominaram as mortas nas primeiras colheitas; estas foram diminuindo nas colheitas seguintes com o aumento das duras e das plântulas normais e anormais. Dasgupta et al. (1982) verificaram que o eixo embrionário do feijão, durante o seu desenvolvimento, apresenta transição do estádio de intolerância para tolerância a dessecação; as observações bioquímicas e de ultra-estruturas, no referido trabalho, indicaram que a dessecação e a reidratação durante os estádios iniciais de desenvolvimento, com intolerância à dessecação, reduziram o metabolismo e a integridade do eixo; já durante o estádio tolerante, esta perturbação não ocorreu, e as sementes ganharam a capacidade de germinar após a hidratação subseqüente. Portanto, nas primeiras colheitas realizadas no presente experimento, provavelmente predominavam as sementes em estádio de intolerância à dessecação, razão do alto percentual de mortas nas sementes secadas fora da vagem (Figura 7); com o desenvolvimento, as sementes passaram a tolerantes, as quais resultaram sementes duras ou germinaram. 
Em contrapartida, as sementes secadas no interior das vagens, já nas primeiras colheitas apresentaram baixa porcentagem de sementes mortas (Figura 8), altas porcentagens de sementes duras e certo percentual de sementes que germinaram produzindo plântulas anormais e outro percentual que originaram plântulas normais. Adams \& Rinne (1981), trabalhando com sementes de soja, verificaram que sementes imaturas, recém-colhidas, úmidas ou secas fora da vagem não eram viáveis, porém se secadas no interior das vagens, mesmo quando com somente $17 \%$ de seu tamanho normal, amadureceram e tornaram-se viáveis, vindo a produzir plantas sadias; constataram assim que, permitindo-se a secagem da vagem em ambiente, as sementes em seu interior completam a expansão, mantém a atividade enzimática, algumas proteínas são modificadas e impõe-se o processo de maturação nas sementes imaturas. Setúbal et al. (1996), por seu turno, em quiabeiro verificaram que para a cv. Santa Cruz47, a secagem das sementes no interior dos frutos propiciou aumentos na germinação das sementes imaturas, mas também aumentou a porcentagem de sementes duras.

Considerando-se que o surgimento da dormência é também um indicativo de progresso de maturação em espécies e cultivares que apresentam esse fenômeno, pode-se inferir que no presente experimento, a presença de maior percentual de sementes duras e também de germinação (Figuras 6, 7 e 8), para as sementes imaturas secadas no interior das vagens, ocorreu por essa condição ter favorecido a maturação, como já observados para outras espécies.

Esses resultados indicam que a colheita de vagens verdes (Tabela 2) e secagem à sombra resultam em sementes com maior porcentagem de sementes duras e menor porcentagem de germinação do que quando colhidas maduras ou secas (Figuras 6 e 8).

Desta forma, se vagens imaturas de mucuna-preta forem colhidas e postas para secar à sombra, isto é lentamente, as sementes imaturas poderão ter acréscimos em tamanho e massa, mas apresentarão alta porcentagem de sementes duras. Esses resultados vêm justificar a recomendação de se realizar a colheita parcelada somente das vagens maduras ou secas na produção de sementes de mucuna-preta, e a enfática proibição de colher-se rácemo com vagens verdes (Kage, 1993).

\section{CONCLUSÃO}

A secagem no interior das vagens promove o desenvolvimento de sementes imaturas, antecipa a formação de sementes duras e aumenta o número dessas nas imaturas comparativamente às sementes secadas em vagens abertas ou após a extração.

\section{REFERÊNCIAS}

ADAMS, C.A.; RINNE, R.W. Seed maturation in soybeans (Glycine $\max$ L. Merr.) is independent of seed mass and of the parent plant, yet is necessary for production of viable seeds. Journal of Experimental Botany, Oxford, v.32, n.128, p.615-620, 1981.

ALVARENGA, E.M.; SILVA, R.F.; ARAUJO, E.F.; CARDOSO, A.A. Influência da idade e armazenamento pós-colheita dos frutos na qualidade de sementes de melancia. Horticultura Brasileira, Brasília, v.2, n.2, p.5-8, 1984.

ARAUJO, E.F.; MANTOVANI, E.C.; SILVA, R.F. Influência da idade e armazenamento dos frutos na qualidade de sementes de abóbora. Revista Brasileira de Sementes, Brasília, v.4, n.1, p.7787, 1982.

BARBEDO, C.J.; NAKAGAWA, J.; MACHADO, J.R. Efeito do tamanho e do armazenamento na dormência de sementes de mucuna-preta. Científica, São Paulo, v.16, n.1, p.97-104, 1988.

BRASIL. Ministério da Agricultura e Reforma Agrária. Regras para análise de sementes. Brasília: SNDA/DNDV/CLAV, 1992. $365 \mathrm{p}$.

CALEGARI, A. Leguminosas para adubação verde de verão no Paraná. Londrina: IAPAR, 1995. 118p. Circular, 80.

CARVAlHO, N. M. Maturação de sementes de algodão (Gossypium hirsutum L.) Semente, Brasília, n.0, p.3-7, 1974.

CARVAlHO, W.A.; ESPÍNDOLA, C.R.; PACCOLA, A.A. Levantamento de solos da Fazenda Lageado. Botucatu: UNESP/ FCA, 1983.95p.

DASGUPTA, J.; BEWLEY, J.D.; YEUNG, E.C. Desiccation-tolerant and desiccation-intolerant stages during the development and germination of Phaseolus vulgaris seed. Journal of Experimental Botany, Oxford, v.33, n.136, p.1045-1057, 1982.

KAGE, H. Produção de sementes de feijão mucuna. In: WUTKE, E.B.; BULISANI, E.A.; MASCARENHAS, H.A.A. I Curso sobre adubação verde no Instituto Agronômico. Campinas: Instituto Agronômico, 1993. p.31-32. Documentos, 35.

MAEDA, J.A.; LAGO, A.A. Germinação de sementes de mucunapreta após tratamentos para superação de impermeabilidade do tegumento. Revista Brasileira de Sementes, Brasília, v.8, n.1, p.79-84, 1986a.

MAEDA, J.A.; LAGO, A.A. Longevidade de sementes de algumas espécies de mucuna. Bragantia, Campinas, v.45, n.1, p.189-194, $1986 b$.

MORAIS, O.M.; SOUZA, R.T. NAKAGAWA, J. Maturação, formas de secagem e qualidade fisiológica de sementes de soja. In: CONGRESSO BRASILEIRO DE SEMENTES, 12., 2001, Curitiba. Informativo ABRATES, Curitiba, v.11, n.2, p.61, 2001a.

MORAIS, O.M.; SOUZA, R.T.; NAKAGAWA, J. Maturação de 
vagens, formas de secagem e qualidade fisiológica de sementes de caupi (Vigna unguiculata (L.) Walp.). In: CONGRESSO BRASILEIRO DE SEMENTES, 12., 2001, Curitiba. Informativo ABRATES, Curitiba, v.11, n.2, p.62, 2001b.

NIMER, R.; CARVALHO, N.M.; LOUREIRO, N.; PERECIN, D. Influência de alguns fatores da planta sobre o grau de dormência em sementes de mucuna-preta. Revista Brasileira de Sementes, Brasília, v.5, n.2, p.111-119, 1983.

OLIVEIRA, J.B.; CAMARGO, M.N.; ROSSI, M.; CALDERON FILHO, B. Mapa pedológico do Estado de São Paulo: legenda expandida. Campinas: Instituto Agronômico, 1999. 64p.

SETUBAL, J.W.; ZANIN, A.C.W.; NAKAGAWA, J. Efeitos da idade dos frutos, métodos e condição de secagem sobre a qualidade de sementes de quiabeiro (Abelmoschus esculentus (L.) Moench) cv. Santa Cruz-47. Revista Brasileira de Sementes, Brasília, v.18, n.1, p.138-142, 1996.

SILVA, T.R.B.; SORATTO, R.P.; MENDONÇA, M.R.; OZEKI, M.;
ARF, O.; SÁ, M.E. Superação da dormência de sementes de mucuna-preta (Mucuna aterrima Piper \& Tracy) através do atrito causado pela areia. In: CONGRESSO BRASILEIRO DE SEMENTES, 12., 2001, Curitiba. Informativo ABRATES, Curitiba, v.11, n.2, p.115, 2001 .

VIEIRA, R.D.; VIEIRA, R.V.; CARVALHO, N.M.; NUNES, O.L.G.S. Maturação de sementes de guandu (Cajanus cajan (L.) Millsp.), labe-labe (Dolichos lablab L.) e mucuna-preta (Styzolobium atterrimum Piper \& Tracy). Científica, São Paulo, v.16, n.1, p.125$131,1988$.

WUTKE, E.B. Adubação verde: manejo da fitomassa e espécies utilizadas no Estado de São Paulo. In: WUTKE, E.B.; BULISANI, E.A.; MASCARENHAS, H.A.A. I Curso sobre adubação verde no Instituto Agronômico. Campinas: Instituto Agronômico, 1993. p.17-29. Documentos, 35.

WUTKE, E.B.; MAEDA, J.A.; PIO, R.M. Superação da dormência de sementes de mucuna-preta pela utilização de "calor seco". Scientia Agricola, Piracicaba, v.52, n.3, p.482-450, 1995. 